\title{
Changes in the epidemiological pattern of sudden infant death syndrome in southeast Norway, 1984-1998: implications for future prevention and research
}

\author{
M Arnestad, M Andersen, Å Vege, T O Rognum
}

\begin{abstract}
Aim-To look for changes in risk factors for sudden infant death syndrome (SIDS) after decrease and stabilisation of the SIDS rate.

Methods-Questionnaires were distributed to parents of 174 SIDS infants, dying between 1984 and 1998, and 375 age and sex matched controls in southeast Norway.

Results-The proportion of infants sleeping prone has decreased, along with the decrease in SIDS rate for the region during the periods studied, but over half of the SIDS victims are still found in the prone position. As the number of SIDS cases has decreased, additional risk factors have become more significant. Thus, after 1993, a significantly increased risk of SIDS is seen when the mother smokes during pregnancy. After 1993, young maternal age carries an increased risk. Maternal smoking and young maternal age are associated with each other. For SIDS victims, an increase in the number of infants found dead while co-sleeping is seen, and the age peak between 2 and 4 months and the winter peak have become less pronounced.

Conclusion-Changes in risk factor profile following the decrease in SIDS rate in the early 1990s, as well as consistency of other factors, provides further clues to SIDS prevention and to the direction of further studies of death mechanisms. (Arch Dis Child 2001;85:108-115)
\end{abstract}

Keywords: SIDS; prone sleeping; low maternal age; smoking; pregnancy

Sudden infant death syndrome (SIDS) is the sudden and unexpected death of any infant or young child, which is unexpected by history, and in which a thorough postmortem examination fails to show an adequate cause of death. ${ }^{1}$

After increasing throughout the 1970s and

Institute of Forensic Medicine, University of Oslo, Rikshospitalet, 0027 Oslo, Norway M Arnestad

$M$ Andersen

Å Vege

T O Rognum

Correspondence to:

Dr Arnestad

marnesta@1abmed.uio.no

Accepted 21 March 2001 80 s, the rate in southeast Norway has decreased since 1990, from 1.8 per 1000 live births in 1989, to less than 0.6 per 1000 live births after 1993. ${ }^{2}$ The decline was rapid from 1990 to 1992 , but has stabilised since 1993. It is well documented that, after national campaigns in several countries, ${ }^{3-5}$ the reduced number of prone sleeping infants caused the rate reduction. Though the prone sleeping position is still a major risk factor for SIDS, the number of infants found dead in the prone position has decreased, and other risk factors such as maternal smoking ${ }^{6} 7$ have become more significant. The age distribution of SIDS victims is claimed to have changed ${ }^{8}$; the same is true for the impact of seasonal variation. ${ }^{9}$ Some risk factors are still controversial; co-sleeping has become increasingly disputed. ${ }^{10}{ }^{11}$ Some studies have shown an increased risk of SIDS associated with co-sleeping, sleeping together with a mother who smokes being the greatest hazard. ${ }^{12}{ }^{13}$ Others have shown no significant relation between co-sleeping and SIDS, ${ }^{14}$ and some have even suggested that co-sleeping might be protective for infants at risk for SIDS. ${ }^{15}$

Our objective was to look for changes in factors associated with increased or reduced risk of SIDS during the time of increasing SIDS rate (1984-89), the period of rapid decline (1990-92), and the time of stable low rates (1993-98).

\section{Materials and methods}

SUBJECTS

The survey was performed as a case-control study. A questionnaire was distributed by mail to 266 parents who had lost a child to SIDS during the period 1984-98, and to 698 control parents. Both cases and controls were from the southeast region of Norway, a region which has 2.5 million inhabitants ( $55 \%$ of Norway's total population). The questionnaires were distributed in 1993 and 1998. The response rate was $69 \%$ in the SIDS parents group, and $75 \%$ in the control parents group. The mean time between death and completing the questionnaire was three years (range 1-8 years). The time of observation was shorter for most of the SIDS cases (until time of death), than for the controls (their first year of life).

All sudden unexpected deaths among children between the second week after birth and 3 years of age were included as SIDS deaths, provided that no explanation for the death was found in the antemortem history or after postmortem examination. ${ }^{16}$

The control infants, matched with the SIDS victims with regard to sex, date of birth $( \pm 1$ day), and place of birth, were picked at random from the national population register. An adjusted questionnaire, leaving out questions concerning death, was sent to the control parents. We excluded answers from SIDS parents where none of the matching controls responded $(n=10)$, as well as answers from controls where the matching SIDS case did not 
Table 1 Factors related to SIDS victims at time of death

\begin{tabular}{|c|c|c|c|c|}
\hline Factor & $\begin{array}{l}1984-1989 \\
n=109 \\
\text { No }(\%)\end{array}$ & $\begin{array}{l}1990-1992 \\
n=26 \\
\text { No }(\%)\end{array}$ & $\begin{array}{l}1993-1998 \\
n=39 \\
\text { No }(\%)\end{array}$ & $\begin{array}{l}\text { p value for } \\
\text { interaction with } \\
\text { period }\end{array}$ \\
\hline Cold last week & $53(52)$ & $7(28)$ & $20(57)$ & 0.06 \\
\hline Cold last day & $36(37)$ & $7(29)$ & $14(40)$ & 0.69 \\
\hline High body temperature last week & $11(11)$ & $2(9)$ & $7(21)$ & 0.30 \\
\hline Face covered or straight down & $36(35)$ & $9(39)$ & $12(32)$ & 0.87 \\
\hline Found outdoors & $29(27)$ & $6(23)$ & $3(8)$ & 0.05 \\
\hline \multicolumn{5}{|l|}{ Age at death } \\
\hline Under 2 months & $4(4)$ & $1(4)$ & $8(20)$ & \multirow[t]{3}{*}{0.01} \\
\hline 2-4 months & $73(67)$ & $13(50)$ & $17(44)$ & \\
\hline$\geqslant 5$ months & $32(29)$ & $12(46)$ & $14(36)$ & \\
\hline \multicolumn{5}{|l|}{ Put down last sleep } \\
\hline Prone & $86(82)$ & $16(64)$ & $7(19)$ & \multirow[t]{3}{*}{$<0.01$} \\
\hline Side & $13(12)$ & $3(12)$ & $10(27)$ & \\
\hline Back & $6(6)$ & $6(24)$ & $20(54)$ & \\
\hline \multicolumn{5}{|l|}{ Sleep position found dead } \\
\hline Prone & $100(93)$ & $22(85)$ & $22(63)$ & \multirow[t]{3}{*}{$<0.01$} \\
\hline Side & $2(2)$ & 0 & $3(9)$ & \\
\hline Back & $5(5)$ & $4(15)$ & $10(28)$ & \\
\hline Co-sleeping at time of death & $2(2)$ & 0 & $13(34)$ & $<0.01$ \\
\hline
\end{tabular}

respond $(n=150)$. No reference sleep was assigned for the control group as the time frame was too long, so we could not control for factors related to SIDS at time of death.

QUESTIONNAIRE

The questionnaires included information about pregnancy, birth, and the first year of life, including feeding habits and dummy use. For SIDS cases, we requested further information on factors concerning the days before death and the day of death. Obstetric factors, parents' smoking habits, social class, maternal age, birth weight, gestational age, birth order, breast feeding, dummy use, sleeping position, cosleeping, age distribution of SIDS victims, season of death, and outdoor sleeping in winter have previously been shown to be associated with either increased or reduced risk of SIDS.

Questions were of a "yes" or "no", or multiple choice nature. Evaluation of social class for both groups was based on occupation at the time of the pregnancy studied, according to the British registrar general's classification. ${ }^{17}$

Ethical approval for the study was obtained from the regional ethical committee.

\section{STATISTICAL ANALYSIS}

Data were analysed by descriptive statistics with frequency distribution and cross tabs calculation using SPSS (Statistical Package for Social Sciences). For trends concerning factors

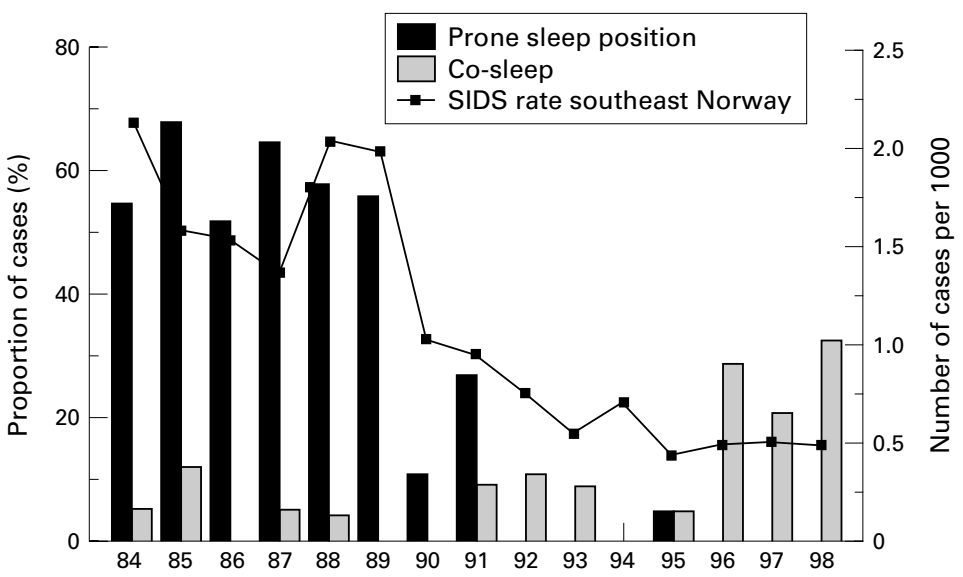

Figure 1 Usual mode of sleep within the control group for the time period studied compared with the SIDS rate for southeast Norway. related to SIDS at time of death, the $\chi^{2}$ test was used (for $2 \times 2$ tables where an expected cell was less than 5, the Fisher exact test was used). Possible selection bias of the participating versus the non-participating population of SIDS cases in the southeast region of Norway was investigated for age and sex distribution using the Mann-Whitney U test. To test for possible recall bias, 50 control families from each period were picked at random and tested for factors where little variation was expected over the time periods studied (birth weight, gestational age, smoking during pregnancy, and dummy use) using the $\chi^{2}$ test.

Conditional logistic regression, taking into account the matching factors between SIDS infants and control infants, was used for calculation of odds ratios (OR) with $95 \%$ confidence intervals (CI) and for analyses of interaction using the EGRET statistical package.

\section{Results}

The study included 174 SIDS families and 375 control families. There were no differences in age and sex distribution between participating and non-participating SIDS infants ( $p=0.99$ and $p=0.47$ respectively), and there was no significant difference between the cohorts studied for each of the different periods $(p=0.25)$. We found no significant change in the control cohorts studied for factors that were presumed to be stable over time (birth weight, gestational age, smoking during pregnancy, and dummy use).

FACTORS SHOWING A CHANGE IN RISK PROFILE ALONG WITH THE CHANGES IN SIDS RATE

For the factors sleeping position and cosleeping among SIDS victims at time of death, age distribution of SIDS victims, seasonal variation of SIDS deaths, and outdoor sleeping, as well as maternal smoking during pregnancy and maternal age, we found a change concerning their significance for the risk of SIDS.

\section{Sleeping position}

The proportion of infants found dead in the prone sleeping position decreased from $93 \%$ in the period with high SIDS rate, to $63 \%$ in the last period of stable rate $(p<0.01$; table 1$)$. In the last period, only $11 \%$ of the SIDS victims generally slept prone, and $19 \%$ had been placed prone for their last sleep, compared to $82 \%$ for both variables in the first period $(\mathrm{p}<0.01$; table 1$)$. Moreover, in the last period, only $20 \%$ of the infants found dead in a prone position both generally slept prone, and were placed prone, for their last sleep. Fifteen per cent of those found prone were put to sleep in a prone position for their last sleep although they were unaccustomed to it, whereas $65 \%$ of SIDS victims found dead in a prone position were neither used to sleeping prone, nor put down prone for their last sleep (secondary prone). Prone sleeping as a usual mode of sleep in the control group has decreased dramatically throughout the periods studied; this decrease parallels the decrease in SIDS rate for the region (fig 1). The risk of SIDS for infants who usually slept in the prone 
Table 2 Factors that showed no interaction with the time periods studied

\begin{tabular}{|c|c|c|c|c|c|c|}
\hline & Factor & $\begin{array}{l}\text { SIDS } \\
n=174 \\
\text { No }(\%)\end{array}$ & $\begin{array}{l}\text { Control } \\
n=375 \\
\text { No }(\%)\end{array}$ & Univariate $O R(95 \% C I)$ & Multivariate OR (95\% CI) & $\begin{array}{l}p \text { value for } \\
\text { interaction with } \\
\text { period }\end{array}$ \\
\hline \multirow[t]{3}{*}{ Pregnancy* } & Complication & $75(44)$ & $124(33)$ & $1.52(1.04$ to 2.23$)$ & 1.27 (0.78 to 2.07$)$ & 0.35 \\
\hline & Disease & $37(22)$ & $36(10)$ & $2.90(1.71$ to 4.91$)$ & $2.85(1.53$ to 5.33$)$ & 0.50 \\
\hline & Father smoking & $76(46)$ & $150(40)$ & $1.25(0.85$ to 1.82$)$ & $1.00(0.60$ to 1.66$)$ & 0.21 \\
\hline \multirow[t]{17}{*}{ Birth ${ }^{\star}$} & Birth weight & & & & & \\
\hline & $<2.5 \mathrm{~kg}$ & $10(6)$ & $17(5)$ & $1.62(0.67$ to 3.92$)$ & $1.81(0.87$ to 3.76$)$ & \multirow[t]{5}{*}{0.83} \\
\hline & $2.5-3.0 \mathrm{~kg}$ & $30(18)$ & $18(12)$ & $1.81(0.98$ to 3.36$)$ & $1.24(0.71$ to 2.20$)$ & \\
\hline & $3.1-3.5 \mathrm{~kg}$ & $31(31)$ & $132(37)$ & $1.0(\mathrm{ref})$ & 1.0 (ref) & \\
\hline & $3.6-4.0 \mathrm{~kg}$ & $32(32)$ & $106(29)$ & 1.27 (0.79 to 2.06$)$ & $1.01(0.50$ to 2.03$)$ & \\
\hline & $>4.0 \mathrm{~kg}$ & $22(13)$ & $61(17)$ & $1.02(0.56$ to 1.86$)$ & $0.65(0.30$ to 1.43$)$ & \\
\hline & Gestational age & & & & & \\
\hline & $<33$ weeks & $8(5)$ & $2(1)$ & 9.70 (2.02 to 46.52$)$ & $13.56(1.25$ to 147.4$)$ & \multirow{5}{*}{0.83} \\
\hline & 33-34 weeks & $9(1)$ & $3(2)$ & $0.57(0.11$ to 2.83$)$ & $1.10(0.13$ to 9.18$)$ & \\
\hline & $35-36$ weeks & $10(3)$ & $10(3)$ & $1.54(0.55$ to 3.33$)$ & $0.59(0.16$ to 2.12$)$ & \\
\hline & $37-38$ weeks & $11(11)$ & $45(11)$ & $1.03(0.57$ to 1.85$)$ & $0.65(0.30$ to 1.43$)$ & \\
\hline & $39-40$ weeks & $139(80)$ & $311(83)$ & $1.0(\mathrm{ref})$ & $1.0(\mathrm{ref})$ & \\
\hline & Birth order & & & & & \\
\hline & Firstborn & $47(27)$ & $147(42)$ & $1.0(\mathrm{ref})$ & $1.0(\mathrm{ref})$ & \multirow{4}{*}{0.49} \\
\hline & No. 2 & $48(38)$ & $137(39)$ & $1.66(1.04$ to 2.65$)$ & $2.42(1.37$ to 4.26$)$ & \\
\hline & No. 3 & $49(22)$ & $52(15)$ & $2.22(1.28$ to 3.84$)$ & $3.56(1.71$ to 7.42$)$ & \\
\hline & No. 4 or later & $23(13)$ & $15(4)$ & $4.32(2.09$ to 8.92$)$ & $8.30(3.16$ to 21.84$)$ & \\
\hline \multirow{13}{*}{$\begin{array}{l}\text { Usual mode of } \\
\text { sleep and } \\
\text { feeding habit } †\end{array}$} & Sleeping position & & & & & \\
\hline & Prone & $109(64)$ & $147(39)$ & $2.71(1.21$ to 6.07$)$ & $1.39(0.61$ to 3.20$)$ & \multirow[t]{4}{*}{0.66} \\
\hline & Side & $24(14)$ & $123(33)$ & $0.40(0.19$ to 0.86$)$ & $0.30(0.12$ to 0.77$)$ & \\
\hline & Side/back & $17(10)$ & $65(17)$ & $0.53(0.24$ to 1.19$)$ & $0.38(0.14$ to 1.12$)$ & \\
\hline & Back & $21(12)$ & $38(10)$ & $1.0(\mathrm{ref})$ & 1.0 (ref) & \\
\hline & Waking at night $\ddagger$ & & & & & \\
\hline & Always & $5(3)$ & $36(10)$ & 1.0 (ref) & 1.0 (ref) & \multirow[t]{5}{*}{0.10} \\
\hline & Often & $6(4)$ & $37(21)$ & $0.48(0.13$ to 1.79$)$ & $0.35(0.08$ to 1.45$)$ & \\
\hline & Sometimes & $7(12)$ & $104(29)$ & $1.36(0.46$ to 4.04$)$ & $1.03(0.31$ to 3.46$)$ & \\
\hline & Seldom & $8(49)$ & $105(29)$ & $6.68(2.05$ to 15.67$)$ & $5.27(1.71$ to 16.27$)$ & \\
\hline & Never & $53(32)$ & $40(11)$ & $9.80(3.33$ to 28.90$)$ & $9.29(2.79$ to 30.85$)$ & \\
\hline & Co-sleeping & $15(9)$ & $24(6)$ & $1.37(0.68$ to 2.77$)$ & $1.66(0.57$ to 4.85$)$ & 0.60 \\
\hline & Breast feeding $>3$ months $\ddagger$ & $124(71)$ & $275(75)$ & $0.81(0.54$ to 1.21$)$ & $1.69(0.90$ to 3.19$)$ & 0.56 \\
\hline \multirow{6}{*}{ Dummy use $\dagger$} & $0-4$ months daytime & & & & & \\
\hline & Ever & $73(55)$ & $218(68)$ & $0.56(0.37$ to 0.85$)$ & $0.51(0.27$ to 0.96$)$ & \multirow{3}{*}{0.68} \\
\hline & Never & $61(45)$ & $102(32)$ & 1.0 (ref) & 1.0 (ref) & \\
\hline & $0-4$ months night-time & & & & & \\
\hline & Ever & $59(47)$ & $203(63)$ & $0.51(0.33$ to 0.77$)$ & $0.36(0.18$ to 0.69$)$ & \multirow[t]{2}{*}{0.83} \\
\hline & Never & $67(53)$ & $117(37)$ & 1.0 (ref) & 1.0 (ref) & \\
\hline \multirow{12}{*}{$\begin{array}{l}\text { Sosioeconomic } \\
\text { factors } \dagger\end{array}$} & Social class mother $\$$ & & & & & \\
\hline & I & $23(13)$ & $32(9)$ & $1.0(\mathrm{ref})$ & 1.0 (ref) & \multirow[t]{5}{*}{0.76} \\
\hline & II & $17(10)$ & $56(15)$ & $0.42(0.19$ to 0.90$)$ & $0.61(0.22$ to 1.71$)$ & \\
\hline & III & $95(55)$ & $208(56)$ & $0.63(0.35$ to 1.14$)$ & $0.57(0.25$ to 1.30$)$ & \\
\hline & IV & $4(2)$ & $7(2)$ & $0.79(0.20$ to 3.04$)$ & $0.25(0.04$ to 1.53$)$ & \\
\hline & $\mathrm{V}$ & $34(20)$ & $68(18)$ & $0.69(0.35$ to 1.37$)$ & $1.29(0.51$ to 3.27$)$ & \\
\hline & Social class father $\$$ & & & & & \\
\hline & I & $31(19)$ & $42(12)$ & 1.0 (ref) & 1.0 (ref) & \multirow[t]{5}{*}{0.19} \\
\hline & II & $30(18)$ & $79(22)$ & $0.51(0.27$ to 0.96$)$ & $0.52(0.22$ to 1.23$)$ & \\
\hline & III & $52(31)$ & $132(36)$ & $0.53(0.30$ to 0.93$)$ & $0.78(0.35$ to 1.74$)$ & \\
\hline & IV & $36(22)$ & $67(18)$ & $0.72(0.39$ to 1.34$)$ & $1.27(0.51$ to 3.21$)$ & \\
\hline & $\mathrm{V}$ & $17(10)$ & $44(10)$ & $0.52(0.25$ to 1.08$)$ & $0.58(0.20$ to 1.72$)$ & \\
\hline
\end{tabular}

*The multivariate model controls for the following variables: disease and complications in pregnancy, birth weight, gestational age, birth order, mother's age at time of pregnancy, mother's and father's smoking habits during pregnancy, and social class/occupational status at the time of pregnancy.

†The multivariate model controls for the following variables: birth weight, gestational age, birth order, breast feeding over three months, waking at night, co-sleeping, sleeping position, dummy use, mother's and father's smoking habit during pregnancy, and social class/occupational status at the time of pregnancy.

$\ddagger$ For SIDS cases breast feeding until time of death or over 3 months.

$\$$ Based on occupation at time of pregnancy studied according to the British registrar general's classification $(I=$ professional, $I I=$ executive, $\mathrm{III}=$ skilled, $\mathrm{IV}=$ semiskilled, $\mathrm{V}=$ unskilled). Housewives and students are classified under III.

position did not increase over the periods studied, as the number of infants usually placed in the prone position has decreased for both the SIDS group and the control group (table 2).

Of the SIDS infants put down in the side position, $56 \%$ were found dead in a prone position, whereas $53 \%$ of those placed on their back were found dead in a prone position. No increased risk of SIDS was seen for infants usually sleeping on the side or varying between side and back, compared to sleeping on the back (table 2).

Co-sleeping, age of SIDS victims, and seasonal variation at time of death

Previously, co-sleeping was uncommon in our region, and few SIDS victims were found dead while sharing a bed with an adult. During the periods studied both the proportion of SIDS infants (3\%, $8 \%$, and $26 \%$ respectively) and control infants $(4 \%, 7 \%$, and $15 \%$ respectively) who routinely co-slept, and the proportion of infants found dead while co-sleeping $(2 \%, 0 \%$, and $34 \%$ respectively) has increased. The infants found dead while co-sleeping were younger (median age at death 2.00 months; range $0.50-5.00$ ) than the total SIDS population (median age at death 3.00 months; range $0.50-26.00 ; p<0.01)$. The number of SIDS victims found dead while co-sleeping has increased significantly (table 1). However, we found no risk of SIDS for infants who usually co-slept, and no changes in risk over the periods could be detected as the number of infants who usually co-slept increased in both the SIDS group and the control group (table 2 ). The increase in co-sleeping as a usual mode of sleep in the control group, over the time period studied, could not be related to changes in the SIDS rate for the region (fig 1).

We found a positive interaction between co-sleeping at time of death for SIDS victims 


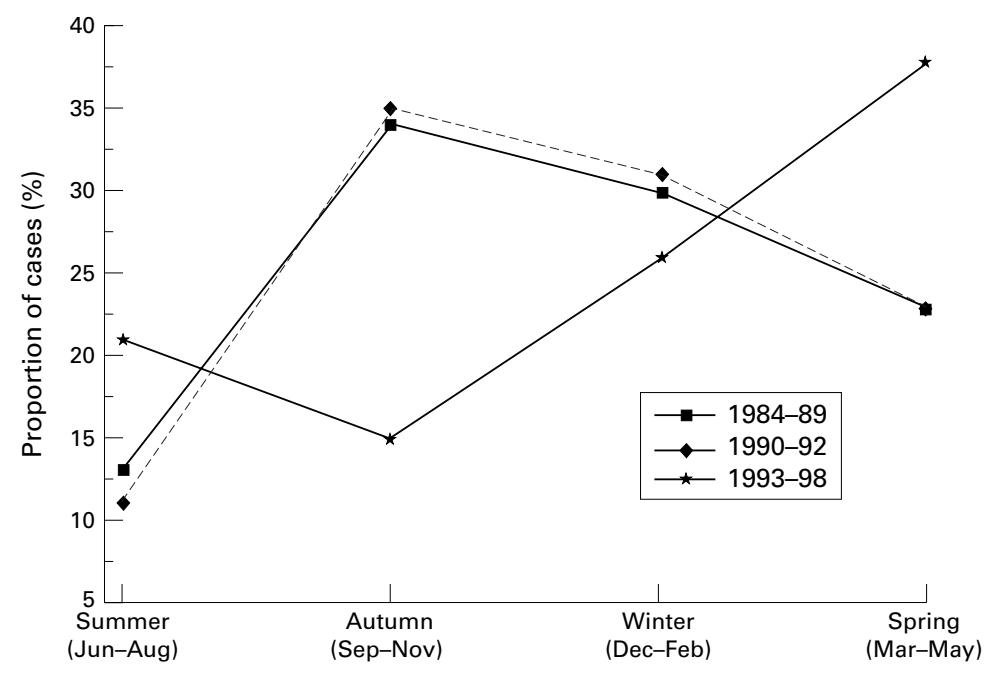

Figure 2 Changes in the seasonal distribution of SIDS deaths. In the last period there are fewer deaths during autumn and winter than in previous periods (interaction with period $p=0.03$ ).
Maternal age

For the first two periods studied (1984-89 and 1990-92), we found no significant relation between maternal age and SIDS. In the last period (1993-98) however, an increased risk in young mothers has become apparent $(<21$ years of age, OR 22.49, CI 2.30 to 219.80; 21-25 years of age, OR 17.77, CI 3.15 to 100.28; table 3). A tendency for an increased risk of SIDS associated with mothers over the age of 35 did not reach statistical significance (OR 5.62; CI 0.71 to 44.37 ).

Positive multiplicative interaction was found between mothers of less than 25 years of age and mothers' smoking (table 4).

FACTORS THAT SHOWED NO CHANGE DURING THE DECREASE IN SIDS RATE

The significance, or lack of significance, of previously proposed risk factors for SIDS (pregnancy complications, birth weight, gestational age, birth order, breast feeding, dummy use, and social class) have not changed in the SIDS population, compared to the control population, during the periods studied. an SIDS risk of 8.63 (CI 1.87 to 39.85 ; $\mathrm{p}<0.01)$. No interaction was found between co-sleeping and birth weight $(\mathrm{p}=0.18)$.

The age distribution of SIDS victims has changed during the periods studied. The age peak at 2-4 months has become less significant in the last period studied (table 1). In the last period there are also fewer deaths during autumn and winter than in previous periods (fig 2). Moreover, in the last period, only $8 \%$ of the SIDS victims were found outdoors, compared to $27 \%$ in the first period and $23 \%$ in the second period (table 1 ).

\section{Maternal smoking during pregnancy}

In the last period studied (1993-98), there has been an increase in the proportion of mothers who smoked during pregnancy in the SIDS group but not in the control group (table 3). In the first and second periods, the proportion of mothers who smoked during pregnancy did not differ significantly between the SIDS group and the controls (OR 1.52, CI 0.94 to 2.37; and OR 0.87 , CI 0.33 to 2.29 , respectively). However, during the period with a stable SIDS rate, there was a statistically significant increased risk of SIDS if the mother smoked during pregnancy (OR 3.37, CI 1.37 to 8.25). The importance of maternal smoking for SIDS risk increased significantly from the second to the third period ( $p=0.04$; table 3$)$.

Fathers' smoking habits during pregnancy were not found to increase the risk of SIDS (table 2). Families where the father smoked but not the mother were, in fact, more common among control cases (19\%) than SIDS cases $(12 \%)(\mathrm{p}=0.04)$.

For the entire study, positive interaction was found between maternal smoking during pregnancy and being found prone $(\mathrm{p}<0.01)$ and between maternal smoking during pregnancy and low birth weight $(p=0.01)$ for the SIDS group.

\section{Pregnancy complications} enced significantly more complications than control mothers, including minor bleeding, proteinuria, and oedema (OR 1.52, CI 1.04 to 2.23), and disease such as infections (OR 2.90, CI 1.71 to 4.91 ; table 2). Disease during pregnancy remained significantly associated with factors related to pregnancy and birth.

Birth weight, gestational age, and birth order Even though there were slightly more SIDS infants with lower birth weight than control infants, we found no significant difference either in the univariate model or when adjusting for factors related to pregnancy and birth (table 2). There were significantly more SIDS infants born before 33 weeks of gestational age in both the univariate and the multivariate model, but no difference between SIDS infants and control infants was found for higher gestational age (table 2). For birth order, the risk of SIDS increased with increasing number of previous siblings in both models (table 2).

\section{Breast feeding and sleeping pattern}

For breast feeding, until the time of death or longer than three months, we found no significant difference between SIDS infants and control infants, either in the univariate model or when controlling for other factors including dummy use (table 2). The proportion of breast fed, co-sleeping infants (approx. 85\% in both groups) was slightly higher than the total number of breast fed infants in both groups (approx. 75\%). The proportion of breast fed infants was slightly lower (approx. $60 \%$ in both groups) when mothers smoked.

Infants who never woke at night spontaneously to feed had an increased risk (OR 9.80, CI 3.33 to 28.90) of dying from SIDS when
During pregnancy, the SIDS mothers experiincreased risk of SIDS after adjustment for 


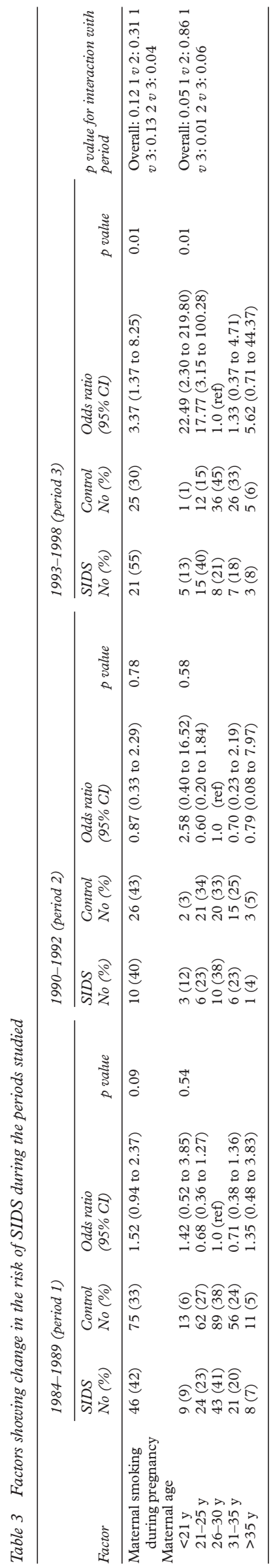

Table 4 Multiplicative interactions between maternal smoking during pregnancy and maternal age for the period of stable SIDS rate; 1993-1998

\begin{tabular}{lllll}
\hline Smoking & $\begin{array}{l}\text { Age } \\
\text { under 25 }\end{array}$ & $\begin{array}{l}\text { SIDS } \\
\text { No (\%) }\end{array}$ & $\begin{array}{l}\text { Controls } \\
\text { No (\%) }\end{array}$ & $\begin{array}{l}\text { Odds ratio } \\
\text { (95\% CI) }\end{array}$ \\
\hline Yes & Yes & $14(38)$ & $4(5)$ & $35.95(5.60$ to 230.60$)$ \\
Yes & No & $7(19)$ & $19(24)$ & $2.61(0.73$ to 9.33$)$ \\
No & Yes & $6(16)$ & $9(11)$ & $7.02(1.36$ to 36.40$)$ \\
No & No & $10(27)$ & $48(60)$ & $1.0($ ref $)$ \\
\hline
\end{tabular}

$\mathrm{p}$ value for interaction $=0.01$.

compared to infants who always woke up during the night (table 2). This was confirmed when we adjusted for factors related to pregnancy, birth, sleep and feeding habits, and dummy use.

\section{Dummy use}

We found a significantly reduced risk of SIDS in infants up to 4 months who used a dummy during the day and night, compared to infants who never used one (daytime OR 0.56, CI 0.37 to 0.85 ; night-time OR 0.51 , CI 0.33 to 0.77 ). The results were confirmed when adjusted for factors related to pregnancy, birth, feeding habits, co-sleeping, and sleeping position.

Social class

No significant difference in social class, for either the mother or the father, could be found between the SIDS families and the control families; there was also no increased risk for SIDS over the time periods studied (table 2). We observed positive interaction between social class and smoking during pregnancy and between social class and young maternal age for both groups.

Signs of infection prior to death and face covered at time of death

For the whole period studied, $46 \%$ of the SIDS victims had a cold during their last week, 33\% had a cold on the last day before death, and $11 \%$ had an increased body temperature during their last week. We found no statistically significant changes in these factors during the periods studied $(p=0.06, p=0.69$, and $\mathrm{p}=0.30$ respectively; table 1 ).

For the whole period, $33 \%$ of the SIDS victims were found dead with their face covered by bedding or face down. This observation did not change significantly over the periods studied ( $p=0.87$; table 1$)$. Eighty nine per cent of those found with their faces covered were found in the prone sleeping position.

\section{Discussion}

Our main findings were that maternal smoking during pregnancy and maternal age have become more significant risk factors for SIDS, after the drop in the SIDS rate and the reduction in SIDS victims found in the prone sleeping position. There was an increase in SIDS victims found dead while co-sleeping. The usual age peak for SIDS deaths, between 2 and 4 months of age, and the seasonal peak during autumn/winter, has become less pronounced.

The response rate of both SIDS parents and control parents was high. We found no difference in age and sex distribution between 
responders and non-responders in the SIDS group, ensuring that our results are representative for all cases in the region studied. Matching SIDS victims and controls for date of birth, sex, and region of birth further reduces confounders. For both SIDS cases and controls there was a time lag, between the period the questions related to, and the time of the actual questionnaire. However, we believe the effect of recall bias was minimal as factors presumed to be stable in the control group over the periods studied were found to be so. Also, in earlier retrospective and prospective studies, recall bias has been found not to influence the results. ${ }^{18} 19$

CHANGES IN THE EPIDEMIOLOGICAL PATTERN OF SIDS

We have shown that changes have occurred in some of the modifiable risk factors, making them even more significant now than when prone sleeping was prominent. The fact that some risk factors have increased or decreased while others have remained unchanged may give further insight into possible mechanisms behind SIDS and clues to which factors should be focused on in future reduction campaigns.

Even though the message that infants should not be placed prone during sleep seems to have reached most parents, ${ }^{5}$ more than half of SIDS victims are still found prone. We found no difference between the number of infants who had turned prone from their sides, compared to from their backs. This might reflect the fact that a larger proportion of SIDS victims are now older than they were 10 years ago, and therefore more likely to change sleeping position of their own accord. We could not show an increased risk of side sleeping compared to supine sleeping as a usual mode of sleep in this study, in contrast to what previous studies have shown. However, because of the lack of a reference sleep for the controls, no comparison between SIDS victims and controls with respect to being put down or found on the side could be performed; likewise no conclusion as to the previously described risk of side sleeping could be made. ${ }^{20}$

Fifteen per cent of the infants found prone during the last period were unaccustomed to prone sleep and $65 \%$ were classified as secondary prone sleepers. An increased risk associated with unaccustomed prone sleep or secondary prone sleep has been shown previously, and reports suggest that lack of experience with a potentially dangerous sleep environment may result in increased risk when these environments are first encountered. ${ }^{21}$

For infants less than 4 months of age ${ }^{8}$ and infants with signs of infection prior to death, ${ }^{82}$ the risk of SIDS while sleeping prone has been shown to be higher during winter than summer. ${ }^{9}$ Prone sleeping has also been associated with excess thermal insulation. Between 1984 and $1989,27 \%$ of SIDS victims in our region were found outdoors, most often during winter. ${ }^{23}$ It is possible that these infants were too heavily wrapped, inducing overheating, which has the most serious implications for the smallest infants with the least mature regulation of temperature. ${ }^{24}$

In a previous study from our region, maternal smoking during pregnancy was not a significantly increased risk, ${ }^{23}$ but it now stands out as a definite risk factor for SIDS. This could be a result of smoking effects previously being overshadowed by the risk of prone sleeping, as the positive interaction found between smoking during pregnancy and being found in the prone sleeping position indicates. Other recent studies of risk factors for SIDS have shown maternal smoking to be of increased importance after the "back to sleep campaigns" and the drop in SIDS rate. ${ }^{67}$ At the 6th International SIDS Conference, Auckland, New Zealand, February 2000, Mitchell concluded that maternal smoking is now an indisputable risk factor for SIDS. A meta-analysis based on eight independent studies, undertaken after the decrease in SIDS rate, disclosed smoking during pregnancy to be among the highest risk factors at the present time (Mitchell, conference presentation). Whether passive smoking is a risk factor for SIDS is still disputed. Nevertheless, it is not thought to have such a strong effect as maternal smoking during pregnancy, ${ }^{25}$ although some studies have found secondary smoking to be a risk factor. ${ }^{26}{ }^{27}$ We did not show significantly increased risk of SIDS if the father smoked during pregnancy.

Smoking is thought to reduce birth weight via disturbance in the intrauterine growth pattern. ${ }^{28} 29$ Though we did not show a significantly increased risk for SIDS associated with low birth weight alone, there was a positive interaction between low birth weight and smoking during pregnancy, making such an association possible. Smoking during pregnancy has also been found to influence the autonomic nervous system, resulting in a deficiency in arousal responsiveness. ${ }^{30}$ We found that SIDS infants used to wake up less frequently to be fed during the night than control infants. Previous studies have also shown an association between SIDS and a behavioural pattern of being sleepier and less active than age matched controls. ${ }^{23} 3132$ This observation may indicate abnormalities in autonomic control or arousal ability, or it could be a result of reduced ATP production. Recent studies have shown that some SIDS victims have mutations in mitochondrial DNA, which may induce ATP depletion. ${ }^{33-35}$ A relatively modest reduction in the ability to produce ATP may constitute a predisposition that could be disastrous under circumstances of increased stress. Finally, the amount of brain stem gliosis in SIDS victims, which is said to be associated with hypoxic-ischaemic events, ${ }^{36}{ }^{37}$ correlates with maternal smoking during pregnancy. ${ }^{38}$

An association between SIDS and socioeconomic factors such as maternal age, maternal smoking during pregnancy, and parents' education or work status has previously been reported. ${ }^{39}$ We found positive interaction between mothers of less than 25 years of age and maternal smoking during pregnancy, for the last period studied. However, young mothers 
who do not smoke also have an increased risk of losing an infant to SIDS, showing low maternal age to be of importance in itself. An interaction was seen between young maternal age and lower social class and between maternal smoking during pregnancy and lower social class, but there were no differences between the SIDS group and the control group and no change over the time periods studied. We could not confirm that the changes shown in risk of SIDS concerning young maternal age and maternal smoking are merely markers of lower socioeconomic status. A limitation of our study is that we did not ask for parents' level of education. Later studies of social indicators as a marker for health in Norway, have shown that education is a better marker than occupation/ income. $^{40}$

Since 1993, co-sleeping has emerged as a more common mode of sleep for both SIDS infants and control infants in our region. At the beginning of the 1990s, a campaign to increase breast feeding in Norway encouraged cosleeping, as this would bring the mother and infant closer, so making night breast feeding easier. ${ }^{41}$ Media focus on SIDS might have generated anxieties in families, ${ }^{42}$ inducing parents to keep the infant close at night. We could not evaluate the effect of this increase in cosleeping at time of death on the risk of SIDS, as no reference sleep could be assigned to the control group. The increase in the number of SIDS cases found dead while co-sleeping, coincides with the stabilisation of the SIDS rate for the region. We speculate whether this indicates that an increase in co-sleeping is the reason why the SIDS rate did not continue to fall.

Co-sleeping may be most dangerous for the smallest infants, as all those who died while co-sleeping were under 5 months of age. However, as we have no information on when control parents stopped co-sleeping, we cannot decide whether this habit is hazardous only to infants in their first months.

Several studies have shown co-sleeping increases the risk of SIDS..$^{10}{ }^{11}$ In the past, the association was attributed to "overlaying" (Holy Bible, I Kings iii, 19), and it has been suggested that parental sedation (often alcohol), fatigue, and obesity may predispose to accidental infantile asphyxia. ${ }^{43}$ One study identified three cases of accidental asphyxia associated with breast feeding related cosleeping. ${ }^{45}$ As there are no simple and unequivocal pathological criteria to distinguish between accidental infantile asphyxia and SIDS, ${ }^{46}{ }^{47}$ cases of overlaying cannot be excluded unless a death scene investigation proves otherwise. Other mechanisms postulated for the increased risk include hypoxia caused by rebreathing of parental expired air, airway obstruction, and thermal stress. ${ }^{10}$ Tufnell and colleagues ${ }^{48}$ showed that co-sleeping infants had higher rectal temperatures than infants sleeping alone, providing support for the thermal stress hypothesis. It is possible that close proximity to a warm adult body and being covered by a heavy, warm adult duvet could result in a higher infant body temperature.
Some authors have reported that the increased risk for co-sleeping infants seems only to apply to infants with smoking mothers. ${ }^{12}{ }^{13}$ Infants of mothers who smoke during pregnancy may have deficient hypoxic arousal responses, and their arousal response to thermal stress may also be blunted..$^{40}$ On the other hand, although several studies have shown an association between co-sleeping and SIDS, it is also possible that parental closeness may have a positive effect on infants. Several studies of mother-infant interaction, while co-sleeping in sleep laboratories, have shown increased arousal responses, better sleep patterns, improved bonding, and increased breast feeding. ${ }^{15} 51$

Birth weight, gestational age, breast feeding, and dummy use did not show a change in trend throughout the different periods. Low birth weight and low gestational age have previously been shown to increase the risk of SIDS. ${ }^{52}$ We were not able to confirm such findings. Ethnically southeast Norway has a relatively homogeneous population with a high standard of living. Medical care is inexpensive and delivery care free of cost, which should contribute to a favourable pregnancy outcome. ${ }^{40}$ Breast feeding has in some studies been found to protect against SIDS. ${ }^{23}{ }^{53}$ However, other, later studies have not been able to confirm this observation. ${ }^{1152}$ We found support for the theory that dummies protect against SIDS, ${ }^{54-57}$ but only in infants younger than 4 months of age. We note that dummies probably make it easier to switch to mouth breathing if nasal occlusion occurs, ${ }^{58}$ and also increase the level of $\mathrm{CO}_{2}$, which is a stimulus for breathing and ensures arousal. ${ }^{59}$ These mechanisms are more important for younger, less mature infants, with less ability to breathe through the mouth and with less developed arousal mechanism, than for older infants.

We conclude that following the reduction in the number of SIDS victims found prone, factors which are now more important include maternal smoking during pregnancy and young maternal age. Other factors have been consistent. This should give clues to preventing SIDS and to further studies of the death mechanisms in SIDS. The young SIDS mothers may represent a socially disadvantaged group. This could be a result of lack of social network and poor education, as well as the habit of smoking during pregnancy. Identification of high risk behaviour/groups may be the way ahead for SIDS prevention.

Dr Arnestad is a fellow of the Norwegian Foundation for Health and Rehabilitation, and Dr Andersen was a fellow of the Norwegian Women's Public Health Association. We would like to thank the Norwegian SIDS Society for support, and Dr phito thank the Norwegian SIDS Society
los Thore Egeland for statistical help.

1 Beckwith JB. Discussion of terminology and definition of the sudden infant death syndrome. In: Bergman AB, Beckwith JB, Ray CG, eds. Sudden infant death syndrome. Proceedings of the Second International Conference on the Causes of Sudden Death in Infants. Seattle: University of Washington Press, 1970:14-22.

2 Statistics Norway. Causes of death 1984-1997. Oslo: Statistics Norway, 1985-1998.

3 Beal S. Sleeping position and sudden infant death syndrome [letter]. Med f A A ust 1988;149:562.

4 de Jonge GA, Burgmeijer RJ, Engelberts AC, et al. Sleeping position for infants and cot death in the Netherlands 198591. Arch Dis Child 1993;69:660-3. 
5 Irgens LM, Markestad T, Baste V, et al. Sleeping position and sudden infant death syndrome in Norway 1967-91. and sudden infant death syndr

6 Daltveit AK, Oyen N, Skjaerven R, Irgens LM. The epidemic of SIDS in Norway 1967-93: changing effects of epidemic of SIDS in Norway 1967-93: chan

7 l'Hoir MP, Engelberts AC, van Well GT, et al. Case-control study of current validity of previously described risk factors for SIDS in the Netherlands. Arch Dis Child 1998;79:38693.

8 Vege A, Rognum TO, Opdal SH. SIDS - changes in the epidemiological pattern in eastern Norway 1984-1996. Forensic Sci Int 1998;93:155-66.

9 Mitchell EA. The changing epidemiology of SIDS following the national risk reduction campaigns. Pediatr Pulmonol 1997;16(suppl):117-19.

10 Mitchell EA, Thompson JMD. Co-sleeping increases the risk of SIDS, but sleeping in the parents' bedroom lowers it. In: Rognum TO, ed. Sudden infant death syndrome. New trends in the nineties. Oslo: Scandinavian University Press, trends in the

11 Fleming PJ, Blair PS, Bacon C, et al. Environment of infants during sleep and risk of the sudden infant death syndrome: 1993 5 case-control study for confidential inquiry into stillbirths and deaths in infancy. Confidential Enquiry into Stillbirths and Deaths Regional Coordinators and Researchers. BMF 1996;313:191-5.

12 Scragg R, Mitchell EA, Taylor BJ, et al. Bed sharing, smoking, and alcohol in the sudden infant death syndrome. New Zealand Cot Death Study Group. BMF 1993;307:1312-18.

13 Blair PS, Fleming PJ, Smith IJ, et al. Babies sleeping with parents: case-control study of factors influencing the risk of the sudden infant death syndrome. CESDI SUDI research group. BMF 1999;319:1457-61.

14 Klonoff-Cohen H, Edelstein SL. Bed sharing and the sudden infant death syndrome. BMF 1995;311:1269-72.

15 Mosko S, Richard C, McKenna J. Infant arousals during mother-infant bed sharing: implications for infant sleep and sudden infant death syndrome research. Pediatrics and sudden infant

16 Cordner SM, Willinger M. The definition of the sudden infant death syndrome. In: Rognum TO, ed. Sudden infant death syndrome. New trends in the nineties. Oslo: Scandinavian University Press, 1995:17-20.

17 Nodtvedt AM, Jacobsen G, Balstad P, Bakketeig LS. [Social class and birth weight]. Tidsskr Nor Laegeforen 1999;119 4455-9.

18 Drews CD, Kraus JF, Greenland S. Recall bias in a case-control study of sudden infant death syndrome. Int $\mathcal{f}$ Epidemiol 1990;19:405-11.

19 Gibbons LE, Ponsonby AL, Dwyer T. A comparison of prospective and retrospective responses on sudden infant death syndrome by case and control mothers. Am f Epidemiol 1993;137:654-9.

20 Scragg RK, Mitchell EA. Side sleeping position and bed sharing in the sudden infant death syndrome. Ann Med 1998;30:345-9.

21 Mitchell EA, Thach BT, Thompson JM, Williams S. Changing infants' sleep position increases risk of sudden
infant death syndrome. New Zealand Cot Death Study. Arch Pediatr Adolesc Med 1999;153:1136-41.

22 Ponsonby AL, Dwyer T, Gibbons LE, et al. Factors potentiating the risk of sudden infant death syndrome associated with the prone position. $N$ Engl f Med 1993;329:377-82.

23 Andersen M, Arnestad M, Rognum TO, Vege A. [Crib death in the eastern regions of Norway 1984-1992. A survey of risk factors]. Tidsskrift for Den Norske Laegeforening 1995;115:34-7.

24 Fleming PJ, Levine MR, Azaz Y, et al. Interactions between thermoregulation and the control of respiration in infants: udden infant death. Acta Paediat 1993;82 (suppl 389):57-9.

25 Alm B, Milerad J, Wennergren G, et al. A case-control study of smoking and sudden infant death syndrome in the Scandinavian countries, 1992 to 1995 . The Nordic Epidemiological SIDS Study. Arch Dis Child 1998;78:329-34.

26 Mitchell EA, Ford RP, Stewart AW, et al. Smoking and the Mitchell EA, Ford RP, Stewart AW, et al. Smoking and the
sudden infant death syndrome. Pediatrics 1993;91:893-6.

27 Blair PS, Fleming PJ, Bensley D, et al. Smoking and the sudden infant death syndrome: results from 1993-5 sudden infant death syndrome: results from 1993-5 case-control study for confidential inquiry into stillbirths and deaths in infancy. Confidential Enquiry into Stillbirths and Deaths Region

28 Schellscheidt J, Jorch G, Menke J. Effects of heavy maternal smoking on intrauterine growth patterns in sudden infan death victims and surviving infants. Eur F Pediatr 1998;157: 246-51.

29 Cooke RW. Smoking, intra-uterine growth retardation and sudden infant death syndrome. Int f Epidemiol 1998;27: 238-41.

30 Franco P, Chabanski S, Szliwowski H, et al. Influence of maternal smoking on autonomic nervous system in healthy infants. Pediatr Res 2000;47:215-20.
31 Einspieler C, Widder J, Holzer A, Kenner T. The predictive value of behavioural risk factors for sudden infant death. Early Hum Dev 1988;18:101-9.

32 Taylor BJ, Williams SM, Mitchell EA, Ford RP. Symptoms, sweating and reactivity of infants who die of SIDS compared with community controls. New Zealand National Cot Death Study Group. I Paediatr Child Health 1996;32:316-22.

33 Silvestri G, Santorelli FM, Shanske S, et al. A new mtDNA mutation in the tRNA(Leu(UUR)) gene associated with maternally inherited cardiomyopathy. Hum Mutat 1994;3: $37-43$.

34 Santorelli FM, Schlessel JS, Slonim AE, DiMauro S. Novel mutation in the mitochondrial DNA tRNA glycine gene associated with sudden unexpected death. Pediatr Neurol 1996;15:145-9.

35 Opdal SH, Rognum TO, Torgersen H, Vege A. Mitochondrial DNA point mutations detected in four cases of sudden infant death syndrome. Acta Paediatr 1999;88:95760 .

36 Naeye RL. Sudden infant death. Sci Am 1980;242:56-62.

37 Kinney HC, Filiano JJ, Harper RM. The neuropathology of the sudden infant death syndrome. A review. $\mathcal{F}$ Neuropathol Exp Neurol 1992;51:115-26.

38 Storm H, Nylander G, Saugstad OD. The amount of brainstem gliosis in sudden infant death syndrome (SIDS) victims correlates with maternal cigarette smoking during pregnancy. Acta Paediatr 1999;88:13-18

39 Daltveit AK, Irgens LM, Oyen N, et al. Sociodemographic risk factors for sudden infant death syndrome: associations with other risk factors. The Nordic Epidemiological SIDS Study. Acta Paediatr 1998;87:284-90.

40 Arntzen A, Samuelsen S, Magnus P, Bakketeig L. Birth weight related to social indicators in Norway. Eur $\mathcal{F}$ Public Health 1994;4:92-7.

41 Børresen HC. Brysternæring. Nattamming. In: Tveterås E, ed. Spedbarnsboken. Stavanger: Sandviks Bokforlag as, 1993:50-2.

42 Pharoah P. Bed-sharing and sudden infant death [comment]. Lancet 1996;347:2.

43 Bass M, Kravath RE, Glass L. Death-scene investigation in sudden infant death. $N$ Engl f Med 1986;315:100-5.

44 Gilbert-Barness E, Hegstrand L, Chandra S, et al. Hazards of mattresses, beds and bedding in deaths of infants. Am $\mathcal{F}$ Forensic Med Pathol 1991;12:27-32.

45 Byard RW. Is breast feeding in bed always a safe practice? $\mathcal{F}$ Paediatr Child Health 1998;34:418-19.

46 Berry PJ. Intra-alveolar haemorrhage in sudden infant death syndrome: a cause for concern? [editorial; comment]. $\mathcal{F}$ Clin Pathol 1999:52:553-4.

47 Rognum TO. Definition and pathological features. In: Byard $\mathrm{RW}$, Krous HF, eds. Sudden infant death syndromeproblems, progress and possibilities. London: Edward Arnold, 2001:4-30.

48 Tuffnell CS, Petersen SA, Wailoo MP. Higher rectal temperatures in co-sleeping infants. Arch Dis Child $1996 ; 75: 249-50$

49 Lewis KW, Bosque EM. Deficient hypoxia awakening response in infants of smoking mothers: possible relationship to sudden infant death syndrome. $\mathcal{F}$ Pediatr 1995;127: 691-9.

50 Mitchell EA. Co-sleeping and sudden infant death syndrome. Lancet 1996;348:1466.

51 McKenna JJ, Mosko SS, Richard CA. Bedsharing promotes breastfeeding. Pediatrics 1997;100(2 Pt 1):214-19.

52 Mitchell EA, Tuohy PG, Brunt JM, et al. Risk factors for sudden infant death syndrome following the prevention campaign in New Zealand: a prospective study. Pediatrics 1997;100:835-40.

53 Ford RP, Mitchell EA, Scragg R, et al. Factors adversely associated with breast feeding in New Zealand. $\mathcal{F}$ Paediatr Child Health 1994:30:483-9.

54 Mitchell EA, Taylor BJ, Ford RP, et al. Dummies and the sudden infant death syndrome. Arch Dis Child 1993;68: $501-4$.

55 Arnestad M, Andersen M, Rognum TO. Is the use of dummy or carry-cot of importance for sudden infant death? Eur 7 Pediatr 1997;156:968-70

56 Fleming PJ, Blair PS, Pollard K, et al. Pacifier use and sudden infant death syndrome: results from the CESDI/SUDI case control study. CESDI SUDI Research Team. Arch Dis Child 1999;81:112-16.

57 L'Hoir MP, Engelberts AC, van Well GT, et al. Dummy use, thumb sucking, mouth breathing and cot death. Eur f Pediatr 1999;158:896-901.

58 Swift PG, Emery JL. Clinical observations on response to nasal occlusion in infancy. Arch Dis Child 1973;48:947-51.

59 Malcolm G, Cohen G, Henderson-Smart D. Carbon dioxide concentrations in the environment of sleeping infants. F Paediatr Child Health 1994;30:45-9. 